\title{
Simplified Equations for Moment and Shear in Bridge Girders Resulting from AASHTO Truck Loading
}

\author{
Seyedshayan Barary ${ }^{1}$, Ahmed Diab ${ }^{1}$, Khaled Sennah ${ }^{1}$ \\ ${ }^{1}$ Ryerson University \\ 350 Victoria St, Toronto, Ontario, Canada \\ sbarary@ryerson.ca; adiab@ryerson.ca; \\ ksennah@ryerson.ca
}

\begin{abstract}
In bridge analysis, bridge designers require the maximum loads applied on bridge traffic lanes in order to determine the appropriate structural design including materials, girder spacing, and cross-section sizes for the bidding procedure. In order to achieve that, designers have to go through an iterative trial and error process which takes a considerable amount of time and may result in overestimation at the bidding stage. In the case of bridge design, there are no such tables which hinders the preliminary assessment of project value and bid cost. As such, this paper outlines a research conducted to develop traffic load equations and tables based on the 2020 AASHTO LRFD Bridge Design Specifications. By utilizing this method, engineers will save time in the design process, and reduce project bid cost by minimizing overdesigned and overestimated structural section sizes for project tender documents. In this research, moving load equations and tables were created based on single-lane bridge models for single span and two-span bridge configurations in SAP2000 software. Truck load arrangements, based on AASHTO LRFD design specifications, were applied and results obtained using moving load approach. Finally, the data generated from the parametric study was used to develop empirical expressions for design moment $\left(\mathrm{M}_{\mathrm{T}}\right)$ and shear $\left(\mathrm{V}_{\mathrm{T}}\right)$ for the use by bridge designers.
\end{abstract}

Keywords: AASHTO LRFD, Finite Element Modelling, Bridge Analysis, Load Calculation, Moving Loads, Parametric Study, Project Bid Process, Ready-made Load Tables.

\section{Introduction}

Currently, engineers utilizing AASHTO LRFD Bridge Design Specifications [1] may not have the time to undergo the full design procedure multiple times in order to obtain an acceptable result for the bidding stage. In other words, designers don't have access to ready-made tables or equations to provide them with some relatively accurate insight on the preliminary sizes of structural steel members to be on bridge projects. As a result, tables and equations can help save considerable amount of time and energy in addition to avoiding overestimation in design. As such, this research is conducted to produce moving load tables and equations for applied moment and shear on bridge girders due to AASHTO truck loading to accelerate the design process. The designer can then apply the proper moment and shear distribution factors from AASHTO LRFD to obtain the design values. Diab and Sennah [2] conducted similar research based on the Canadian truck specified in the Canadian Highway Bridge Design Code [3]. AISC produced a manual based on HS20-44 truck loading, dating back to 1986. [4]. However, this manual is outdated since it does include the current AASHTO truck and lane loading specified in the current AASHTO LRFD design specifications. This paper presents the methodology to conduct moving load analysis using SAP2000 software [5] and to develop empirical equations for the moment, shear and support reactions for simple span girders and two-equal-span girders subjected to AASHTO truck loading.

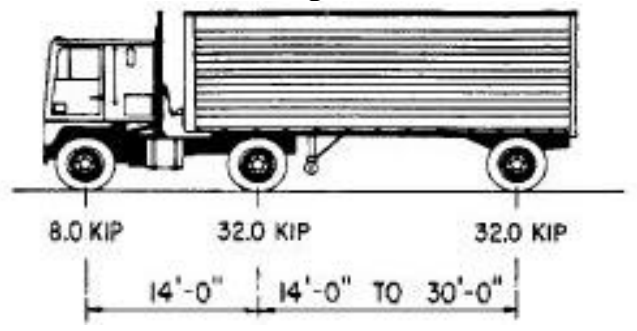

Figure 1: HS20-44 truck (imperial units) as per AASHTO LRFD Specifications [1] 


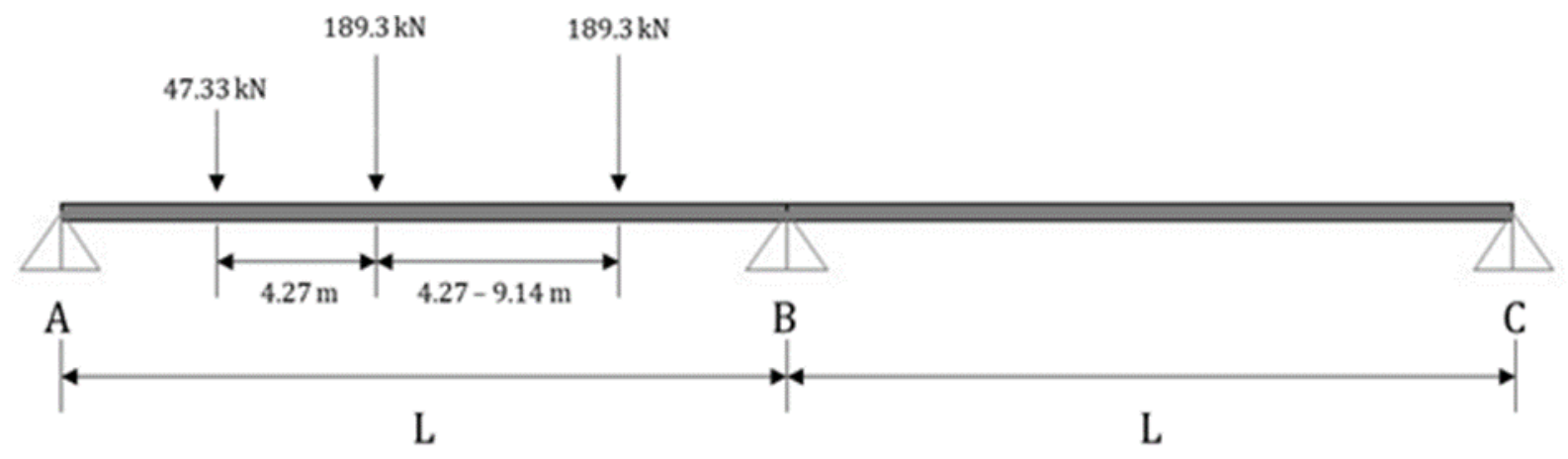

Figure 2: Design truck (including dynamic load allowance, DLA) on a two equal-span beam (metric units) as per AASHTO LRFD Specifications [1]

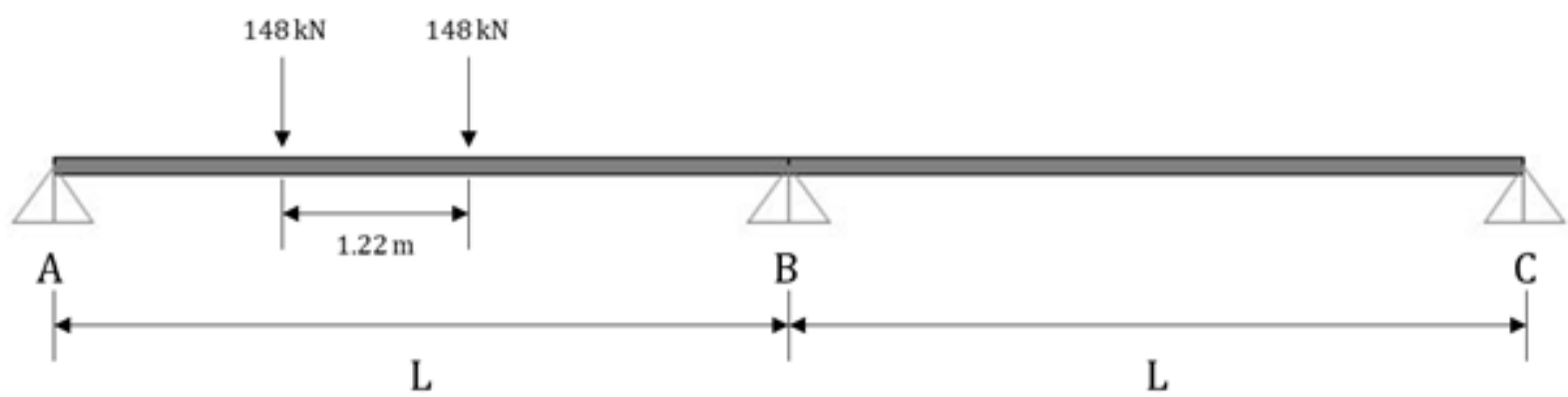

Figure 3: Design tandem (including DLA) on a two equal-span beam (metric units) as per AASHTO LRFD Specifications [1]

\section{Methodology}

AASHTO LRFD Bridge Design Specification specifies two basic vehicles for bridge design, namely: an HS20-44 design truck shown in Figures 1 and 2, and design tandem shown in Figure 3. Each of these design trucks is combined with a uniform load of $9.34 \mathrm{kN} / \mathrm{m}(0.62 \mathrm{kip} / \mathrm{ft})$ placed at longitudinal locations to maximize the moment, shear or reaction values. SAP2000 software was used to conduct finite element analysis of moving loads over a bridge beam of simple span as well as of two-equal spans. Initially, a sensitivity study was conducted to compare different methods of modelling the truck loads, namely: (1) influence-line method, (2) multi-step loading method and, (3) moving load method. Based on the results from the sensitivity study, it was decided to proceed with the moving load method to model the bridge arrangements presented under Table 1 with increments of $2 \mathrm{~m}$ and $4 \mathrm{~m}$ for bridge spans up to and greater than $48 \mathrm{~m}$, respectively. The model for single span and two-span bridge lane loading are shown below in Figures 4 and 5 . The moving loads were considered running over the beam in $0.1 \mathrm{~m}$ increments for higher accuracy of the results although it increased the processing time for the software exponentially with reduced result increment calculation.

Table 1: Bridge configurations

\begin{tabular}{|l|c|}
\hline Bridge spans & Range of analyzed bridge span, L (m) \\
\hline Single span & $6-80$ \\
\hline Two equal spans & $12-80$ \\
\hline
\end{tabular}

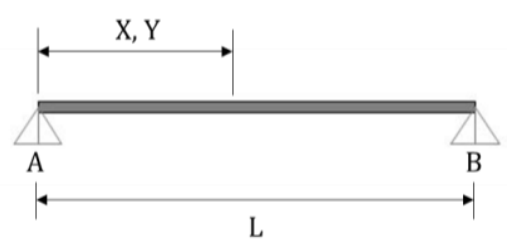

Figure 4: Single span beam

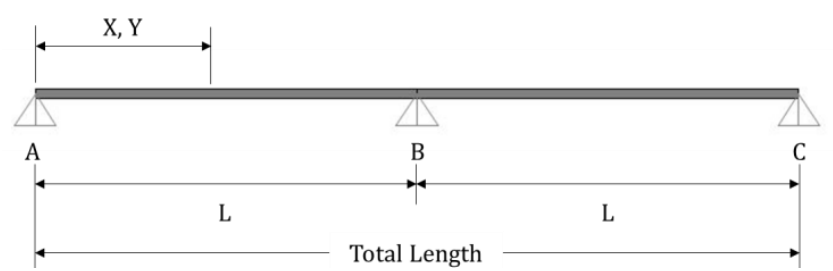

Figure 5: Two-span beam 
As stated in Section 3.6.1.2.3 of the AASHTO LRFD Specifications, the design tandem includes a pair of $111.2 \mathrm{kN}(25$ kips) axles spaced at $1.22 \mathrm{~m}$ (4 ft.) apart, with an impact factor of 0.33 (Section 3.6.2.1), which translates into a pair of 148 $\mathrm{kN}$ axles as depicted in Figure 3. Section 3.6.1.3.1 specifies the design lane load as $9.34 \mathrm{kN} / \mathrm{m}(0.64 \mathrm{kip} / \mathrm{ft})$ without the inclusion of the impact factor [1]. The "Vehicle Remains Fully in Path" setting in SAP2000 software is left disabled. Enabling this setting skips the cases where the moving load does not fit the bridge longitudinally. This is especially significant for shorter spans and longer truck configurations. AASHTO LRFD Section 3.6.1.3.1 also states that the combination of design truck and design lane load should be considered. The design truck in Figure 1 is comprised of 3 axles of $35.6 \mathrm{kN}$ ( 8 kips), $142.3 \mathrm{kN}$ (32 kips) and $142.3 \mathrm{kN}$ (32 kips), respectively. The distance between the first and second axles is $4.27 \mathrm{~m}$ (14 ft.) while the distance between the second and the third axles varies from $4.27 \mathrm{~m}(14 \mathrm{ft}$.) to $9.14 \mathrm{~m}(30 \mathrm{ft})$. It should be noted that in order to obtain the extreme force effect, the distance between the second and third axles should be minimum. Figure 2 shows the design truck axle loads including the impact factor. The greater moment or shear resulting from the analysis of the beam under the design tandem and design truck was considered to develop the empirical equations for design purposes. It is worth mentioning that no underestimation was considered for the equations developed.

\section{Moving Load Analysis versus Multi-Step Analysis in SAP2000 Software}

A sensitivity study was conducted to examine whether there is a difference between the multi-step loading method and the moving load method in SAP2000 software. Analysis using these two alternatives were evaluated and results are tabulated in Table 2 for span lengths 20, 30, 40, 60 and $80 \mathrm{~m}$. Results show insignificant difference between the two methods. Previous research conducted by Diab [8] suggested that moving load method is a better tool since it has better discretization and estimate. In the current study, the moving load method was used to conduct the parametric study to produce data required to develop the empirical equations for moment, shear and support reactions.

Table 2: Moving load vs multi-step analysis comparison

\begin{tabular}{|c|c|c|}
\hline Span Length "L" (m) & Moment using moving load method (kN.m) & Moment using multi-step analysis method (kN.m) \\
\hline 20 & 1311.78 & 1309.84 \\
\hline 30 & 2183.03 & 2180.91 \\
\hline 40 & 3060.71 & 3056.42 \\
\hline 60 & 4824.40 & 4819.43 \\
\hline 80 & 6592.90 & 6583.00 \\
\hline
\end{tabular}

\section{Parametric Equations for Single Span Bridge Arrangement}

In this section, the results for the single span bridge configurations are presented along with the confidence ratio associated with the results $\left(\mathrm{R}^{2}\right)$.

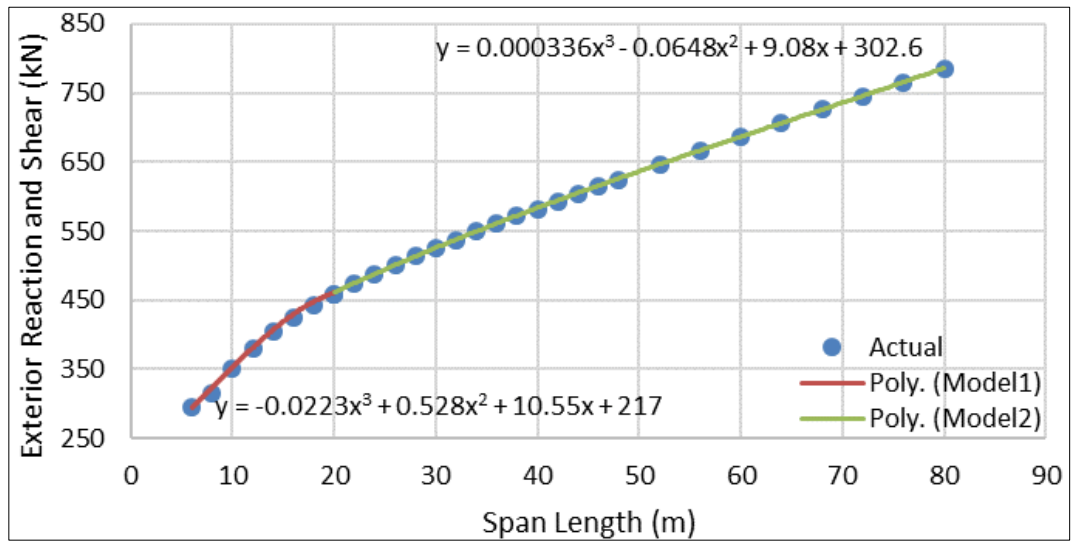

Figure 6: Single span support reaction and developed equation results 


\subsection{Maximum Reaction and Shear}

Figure 6 shows the maximum support reaction or beam shear with the change of bridge span. Based on this data, equations 1 and 2 were developed for beam spans up to $20 \mathrm{~m}$ and from to 20 to $80 \mathrm{~m}$, respectively. Table 3 shows a sample of the analysis results obtained for maximum support reaction and beam shear in a single span bridge compared to the developed model. Similar results were obtained for the other results presented in this paper.

$$
\begin{array}{ll}
R_{T}(A)=-0.0223 L^{3}+0.528 L^{2}+10.55 L+217 k N, R^{2}=0.99 & \text { For } 6 \mathrm{~m} \leq L \leq 20 \mathrm{~m} \\
R_{T}(A)=0.000336 L^{3}-0.0648 L^{2}+9.08 L+302.6 \mathrm{kN}, R^{2}=0.99 & \text { For } 20 \mathrm{~m} \leq L \leq 80 \mathrm{~m}
\end{array}
$$

Table 3: Single span support reaction and developed equation results

\begin{tabular}{|c|c|c|c|}
\hline $\mathbf{L}(\mathbf{m})$ & Actual $(\mathbf{k N})$ & Model $(\mathbf{k N})$ & Percentage difference in actual and predicted values \\
\hline 40 & 582.41 & 583.62 & $0.21 \%$ \\
\hline 42 & 593.20 & 594.54 & $0.23 \%$ \\
\hline 44 & 603.85 & 605.28 & $0.24 \%$ \\
\hline 46 & 614.39 & 615.86 & $0.24 \%$ \\
\hline 48 & 624.82 & 626.29 & $0.24 \%$ \\
\hline 52 & 645.45 & 646.78 & $0.21 \%$ \\
\hline 56 & 665.79 & 666.87 & $0.16 \%$ \\
\hline 60 & 685.92 & 686.69 & $0.11 \%$ \\
\hline 64 & 705.86 & 706.37 & $0.07 \%$ \\
\hline 68 & 725.65 & 726.05 & $0.05 \%$ \\
\hline 72 & 745.33 & 745.85 & $0.07 \%$ \\
\hline 76 & 764.89 & 765.89 & $0.13 \%$ \\
\hline 80 & 784.37 & 786.31 & $0.25 \%$ \\
\hline
\end{tabular}

\subsection{Maximum Positive Moment}

Figure 7 shows the maximum positive moment with the change of span in simply-supported bridge beams. Equations 3 and 4 were developed for beam spans up to $18 \mathrm{~m}$ and from to 18 to $80 \mathrm{~m}$, respectively. Good agreement between the developed equations and the analytical results.

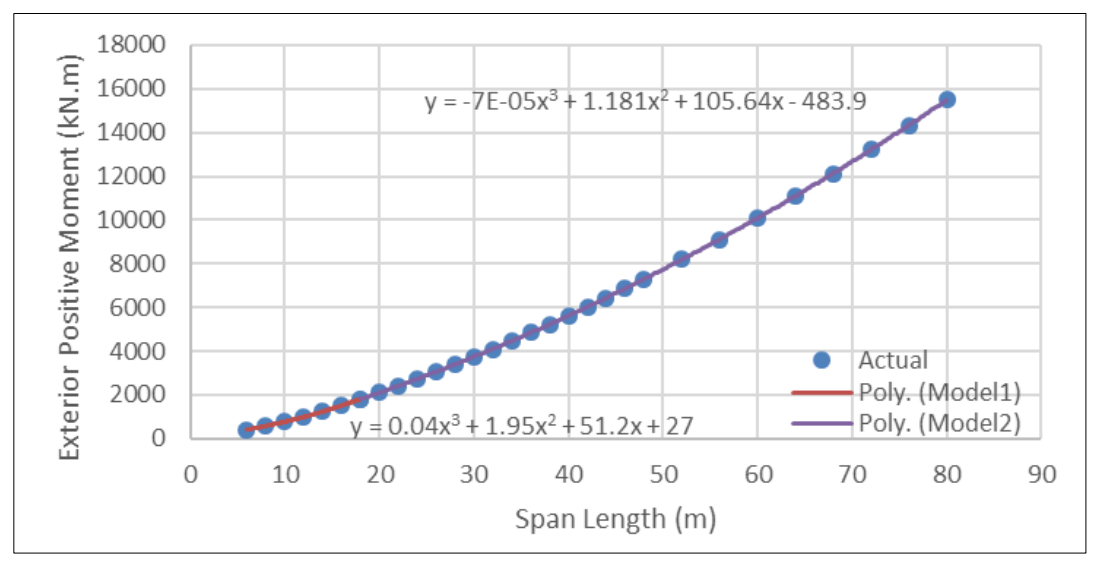

Figure 7: Single span maximum positive moment and developed equation results

$M_{T}(A B)=0.04 L^{3}+1.95 L^{2}+51.2 L+27 k N . m, R^{2}=0.99$

$M_{T}(A B)=-7 \times 10^{-05} L^{3}+1.181 L^{2}+105.64 L-483.9 k N . m, R^{2}=1$
For $6 m \leq L \leq 18 m$

For $18 m \leq L \leq 80 m$ 


\section{Parametric Equations for Two-Span Bridge Arrangement}

In this section, the results for the two-span bridge arrangement are presented along with the confidence ratio associated with the results $\left(\mathrm{R}^{2}\right)$.

\subsection{Maximum Reaction and Shear at Exterior Support}

Figure 8 shows the maximum support reaction or beam shear with the change of bridge span for a two-span beam due to AASHTO truck loading. Based on the data generated from the parametric study, equation 5 was developed for beam spans from to 12 to $80 \mathrm{~m}$.

$$
R_{T}(A)=0.000768 L^{3}-0.134 L^{2}+12.15 L+238 k N, R^{2}=0.99 \quad \text { For } 12 \mathrm{~m} \leq L \leq 80 \mathrm{~m}
$$

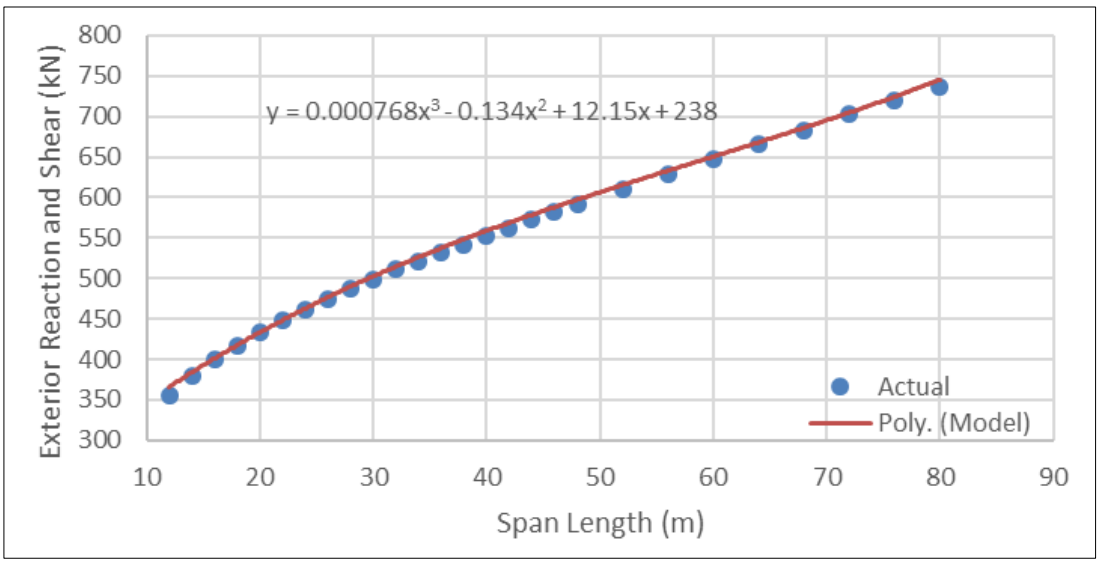

Figure 8: Exterior support reaction and developed equation results for a two-span beam

\subsection{Maximum Reaction at Interior Support}

Figure 9 shows the maximum reaction at the interior support of a two-span beam due to AASHTO truck loading. Based on the data generated from the analysis, equations 6 and 7 were developed for beam spans from to 12 to $20 \mathrm{~m}$ and from 20 to $80 \mathrm{~m}$, respectively.

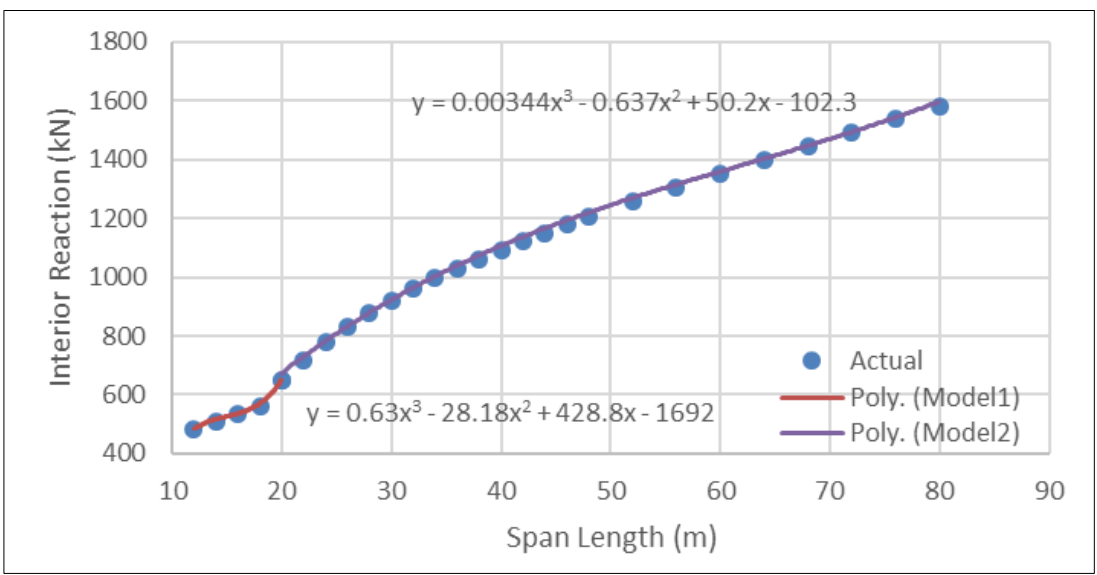

Figure 9: Interior support reaction and developed equation results for a two-span beam

$R_{T}(B)=0.63 L^{3}-28.18 L^{2}+428.8 L-1692 k N, R^{2}=0.99$

$R_{T}(B)=0.00344 L^{3}-0.637 L^{2}+50.2 L-102.3 k N, R^{2}=0.99$
For $12 m \leq L \leq 20 m$

For $20 m \leq L \leq 80 m$ 


\subsection{Maximum Shear Left of the Interior Support}

Figure 10 shows the maximum shear at the left of the interior support of a two-span beam due to AASHTO truck loading. Based on the data generated from the analysis, equations 8 and 9 were developed for beam spans from to 12 to $22 \mathrm{~m}$ and from 22 to $80 \mathrm{~m}$, respectively.

$$
\begin{array}{ll}
V_{T}(B L)=0.0178 L^{3}-1.21 L^{2}+35.4 L+135 k N, R^{2}=0.99 & \text { For } 12 \mathrm{~m} \leq L \leq 22 \mathrm{~m} \\
V_{T}(B L)=0.000249 L^{3}-0.0485 L^{2}+9.11 L+339.3 k N, R^{2}=0.99 & \text { For } 22 \mathrm{~m} \leq L \leq 80 \mathrm{~m}
\end{array}
$$

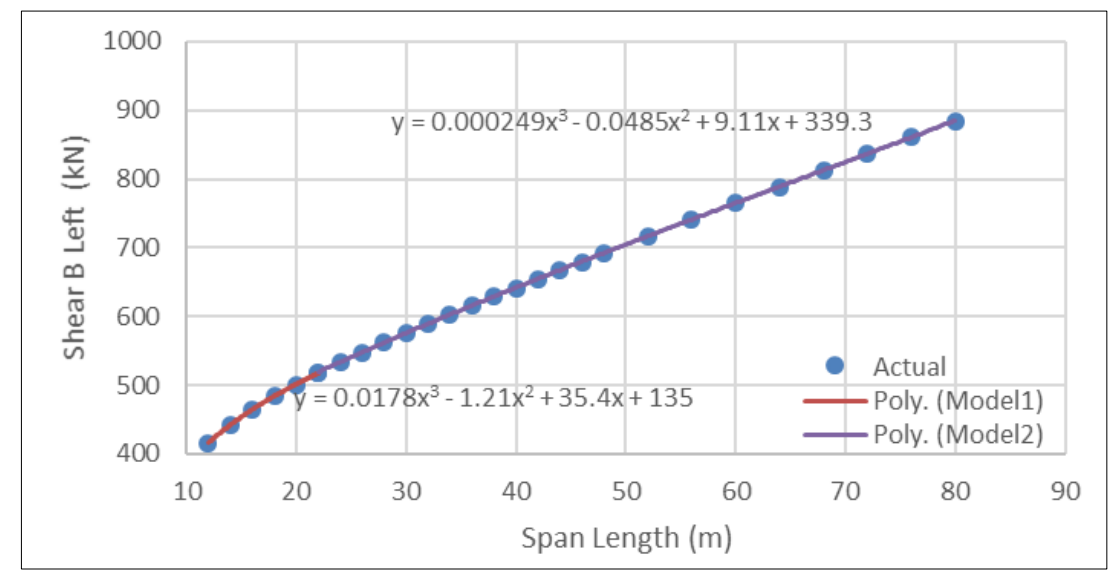

Figure 10: Maximum shear at left of the interior support and developed equation results for a two-span beam

\subsection{Maximum Positive Moment}

Figure 11 shows the maximum positive moment with the change of span in a two-span bridge beam. Equations 10 and 11 were developed for beam spans up to $22 \mathrm{~m}$ and from to 22 to $80 \mathrm{~m}$, respectively. Good agreement between the developed equations and the analytical results.

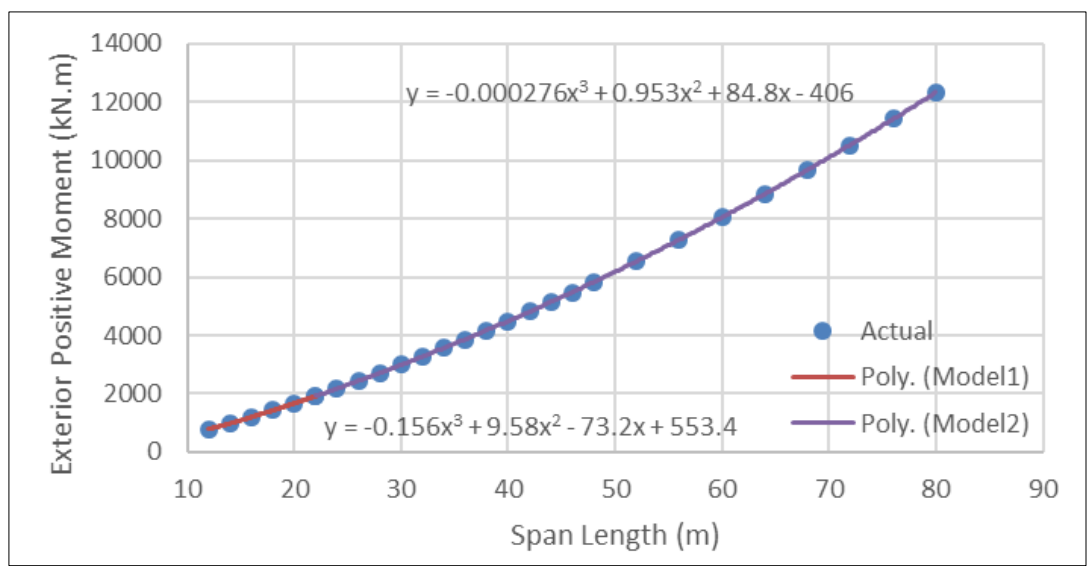

Figure 11: Maximum positive moment and developed equation results for a two-span beam

$$
\begin{aligned}
& M_{T}(A B)=-0.156 L^{3}+9.58 L^{2}-73.2 L+553.4 k N . m, R^{2}=0.99 \\
& M_{T}(A B)=-0.000276 L^{3}+0.953 L^{2}+84.8 L-406 k N . m, R^{2}=1
\end{aligned}
$$

For $12 m \leq L \leq 22 m$

For $22 m \leq L \leq 80 m$

\subsection{Maximum Negative Moment}

Figure 12 shows the maximum negative moment values in a two-span beam. Equations 12 and 13 were developed for beam spans up to $22 \mathrm{~m}$ and from to 22 to $80 \mathrm{~m}$, respectively. Good agreement between the developed equations and the analytical results. 
$M_{T}(B)=-1.111 L^{3}+60.85 L^{2}-934.2 L+4884 k N . m, R^{2}=0.99$

$M_{T}(B)=0.00218 L^{3}+0.669 L^{2}+96.2 L-469 k N . m, R^{2}=0.99$
For $12 m \leq L \leq 22 m$

For $22 m \leq L \leq 80 m$

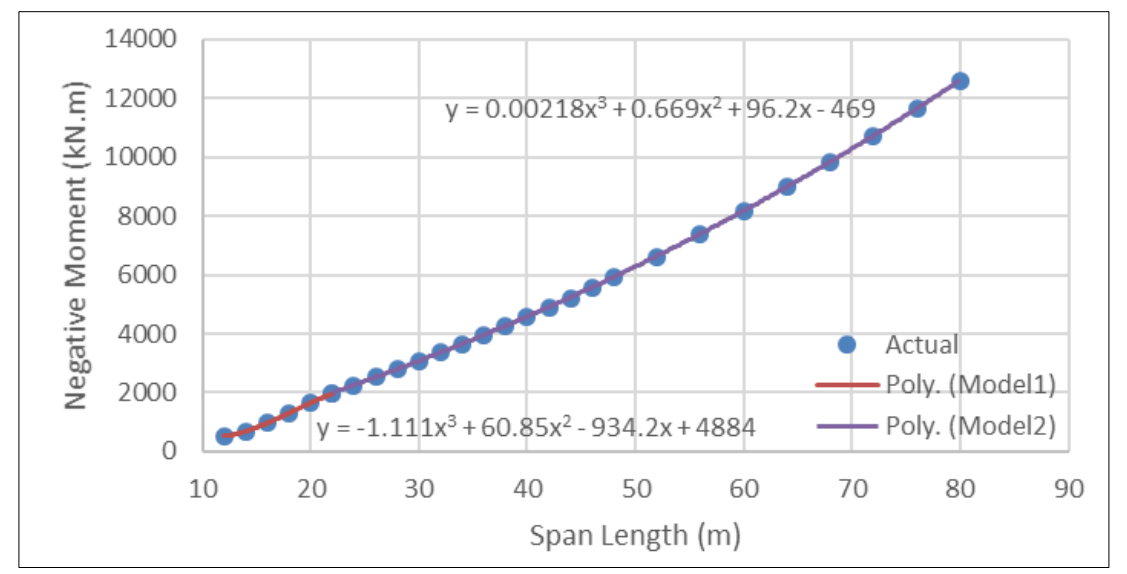

Figure 12: Maximum negative moment and developed equation results for a two-span beam

\section{Conclusions}

Using the AASHTO LRFD design truck loading conditions and utilizing the finite element modelling using SAP2000 software, single-span and two-span bridge beams were analysed to determine the specified moment, shear and support reactions due to a traffic lane loading. The results from the analysis of beams under moving loads were used to develop empirical expressions for the moment, shear and support reaction in a bridge beam due to AASHTO live loading. Engineers will then multiply these values with the proper live load distribution factor and the live load factor per AASHTO LRFD Bridge Design Specifications to obtain the factored moment and shear that are required to design the bridge beams at ultimate limit state. The empirical equations were developed with great accuracy to provide engineer with confidence in using them to accelerate the design of new bridges and the evaluation of existing ones.

\section{Acknowledgements}

The authors would like to acknowledge the support of the Natural Sciences and Engineering Research Council of Canada (NSERC) and NSERC Undergraduate Student Research Assistant Program (NSERC-USRA).

\section{References}

[1] American Association of State Highway and Transportation Officials, AASHTO LRFD Bridge Design Specifications. Washington, DC, 2020.

[2] A. Diab and K. Sennah, "Simplified Equations for Moment and Shear Values in Bridge Girders Resulting from Truck Loading" in Proceedings of the Short and Medium Span Bridge Conference, Quebec, Canada, 2018, pp. 133-1 - 133-9.

[3] Canadian Standards Association, Canadian Highway Bridge Design Code. Mississauga, Ontario, 2019.

[4] American Institute of Steel Construction, Moments, Shears and Reactions for Continuous Highway Bridges. Chicago, IL, 1986.

[5] CSI, "SAP2000 Integrated Software for Structural Analysis and Design," Computers and Structures Inc., Berkeley, California, 2020.

[6] A. Diab, "Development of a Quick Design Method for Composite Concrete Slab-Over Steel I-Girder Bridges for Project Bidding”, M.A.Sc. Thesis, Department of Civil Engineering, Ryerson University, Toronto, Canada, 2018. 